\title{
O MÉDICO, O MONSTRO E OS OUTROS
}

Vinicius Lucas de Souza (UNESP) Aparecido Donizete Rossi (UNESP)

Recebido em 30 set 2016. Vinicius Lucas de Souza - Graduado em Letras Aprovado em 14 out 2016. (Português/Inglês/Alemão) pela UNESP Faculdade de Ciências e Letras de Araraquara (2015) e mestrando no Programa de Pós-Graduação em Estudos Literários pela mesma universidade. Desenvolve pesquisa na área de Literaturas Estrangeiras Modernas, com ênfase em Literaturas de Língua Inglesa e Literatura Gótica, focando no motivo literário do Duplo e suas transformações na Ficção. Contato: viniciuslucassouza@gmail.com.

Aparecido Donizete Rossi - Graduado em Letras (Português/Inglês) pela UNESP Faculdade de Ciências e Letras de Araraquara (2003), Mestre em Estudos Literários pela mesma universidade (2006) e Doutor em Estudos Literários também pela UNESP Araraquara (2011). Atua em Letras, na área de Literaturas de Língua Inglesa, e desenvolve pesquisas principalmente sobre as Manifestações do Gótico, do Fantástico e da Fantasia na Literatura, a vida e a obra de Kate Chopin, Literatura e Desconstrução e Literatura e Psicanálise.

Resumo: Visualizando-se o conto "William Wilson" (1839), de Edgar Allan Poe, o tema do duplo (Doppelgänger) conduz toda a narrativa. Com a premissa de que esse conto é um marco nessa 
temática, como afirma Otto Rank, estudioso de tal motivo, pode-se dizer que a denominação "Complexo de William Wilson" seja adequada para representar três elementos que emergem da narrativa mencionada de Poe: a existência de uma segunda personagem que compartilha traços físicos e psíquicos da personalidade "original"; a existência do Unheimliche (tal como definido por Sigmund Freud em seu ensaio "O 'estranho'" ("Das Unheimliche", 1919)), o familiar e estranho convergindo para uma mesma personagem (o outro; o duplo); e o espelho, auxiliador da manifestação do Doppelgänger. Tendo em mente o referido Complexo (que é identificado pelo conto citado de Poe), o que se almeja demonstrar neste artigo é como o Complexo de William Wilson é revisto no romance $O$ médico e o monstro (Strange Case of Dr. Jekyll and Mr. Hyde, 1886), de Robert Louis Stevenson. Com uma ampliação da abordagem da segunda entidade, uma inovação no elemento unheimlich e modificado o espectro de atuação e significação do espelho, o romance em questão ressignifica o tratamento do Complexo de William Wilson. Com a revisão desses três fatores, Henry Jekyll, Edward Hyde e o "hóspede" dessas duas personalidades, bem como os jogos fractários, metaficcionais e catóptricos, promovem a insurgência do que aqui se denominou Paradoxo Jekyll-Hyde.

Palavras-chave: $O$ médico e o monstro; Robert Louis Stevenson; Duplo; Complexo de William Wilson; Paradoxo Jekyll-Hyde.

Abstract: By visualising Edgar Allan Poe's "William Wilson" (1839), the theme of the double (Doppelgänger) orients the whole narrative. On the assumption that this short story is a landmark on this thematics, as claimed by Otto Rank, a scholar on such motif, it is possible to say the denomination "William Wilson Complex" is adequate for representing three elements that emerge in Poe's mentioned narrative: 
the existence of a second character who shares physical and psychic features of the "original" personality; the existence of the Unheimliche (as defined by Sigmund Freud in his essay "The 'Uncanny"' ("Das Unheimliche", 1919)), the familiar and uncanny converging into the same character (the other; the double); and the mirror, auxiliary of the manifestation of the Doppelgänger. Considering the referred Complex (which is identified by Poe's short story in question), this paper intends to demonstrate how the William Wilson Complex is revised in the novel Strange Case of Dr. Jekyll and Mr. Hyde (1886), by Robert Louis Stevenson. By broadening the approach of the second entity, innovating the unheimlich element, and modifying the spectrum of performance and signification of the mirror, the novel in question ressignifies the treatment of the William Wilson Complex. With the revision of these three factors, Henry Jekyll, Edward Hyde, and the host to such personalities, as well as the fragmentary, metafictional and catoptric games, promote the insurgence of what here is denominated the Jekyll-Hyde Paradox.

Keywords: Strange Case of Dr. Jekyll and Mr. Hyde; Robert Louis Stevenson; Double; William Wilson Complex; Jekyll-Hyde Paradox.

\section{INTRODUÇÃO' ${ }^{1}$}

Visualizando-se o conto "William Wilson" (1839), de Edgar Allan Poe, fato é que o tema do duplo (Doppelgänger) conduz o fio narrativo. Em seu livro $O$ duplo (Der Doppelgänger, 1925), Otto Rank profere a seguinte afirmação ao comentar o referido

10 texto que ora se apresenta é fruto de uma pesquisa que teve início com uma Iniciação Científica financiada pela Fundação de Amparo à Pesquisa do Estado de São Paulo (FAPESP, processo 2013/16530-9). Essa pesquisa continua em desenvolvimento atualmente, em nível de mestrado, sob financiamento do Conselho Nacional de Desenvolvimento Científico e Tecnológico (CNPq). O que aqui se apresenta constitui resultados concretos auferidos até o momento. 
conto: "Uma representação da matéria do duplo que serviu de modelo para alguns artistas posteriores foi dada por Edgar Allan Poe em seu conto 'William Wilson'”' (2013, p.46). Tendo em mente essa narrativa como um marco na consolidação da temática do duplo não apenas no Romantismo, mas também no conjunto da tradição literária ocidental, pode-se dizer que a denominação "Complexo de William Wilson" é adequada para plasmar a emergência de uma segunda entidade que simularia a aparência física e traços psíquicos da "original". Em suma, podese tomar tal asserção - "Complexo de William Wilson" - como um sinônimo conceitual para duplo.

Antes de se mergulhar em reflexões sobre esse Complexo, fazse importante notar que o termo "Complexo de William Wilson" já fora utilizado por Renata Soares Junqueira em sua pesquisa intitulada "O complexo de 'William Wilson'": crise de consciência e perquirição de identidade no moderno teatro português", na qual a pesquisadora propôs

[...] uma reflexão crítica sobre o teatro português produzido desde o Simbolismo até à década de 1950. Trata-se de investigar, nesta produção, como se expressam o mito do Duplo e a temática que este mito sugere: a da identidade do homem moderno, sujeito dissociado, esquartelado pelo processo civilizacional. (2004, p.1)

O que aqui se propõe, no entanto, não participa do mesmo uso terminológico engendrado por Junqueira. Para além disso, busca-se ressignificar o referido Complexo ao imbuí-lo com certas características que, como se verificará na análise que segue, emergem especificamente da obra de Poe. 
Com a materialização desse Complexo a partir do conto de Poe, depreendem-se três elementos que assombram seu protagonista:

[...] uma materialização de uma segunda entidade, que compartilharia traços físicos e detalhes da personalidade da personagem original; a existência do Unheimliche, o familiar e estranho convergindo para uma mesma personagem; e o espelho, auxiliador da manifestação do Doppelgänger. (SOUZA; ROSSI, 2015, p.9 - grifo dos autores)

No novelo narrativo do conto em questão, a personagem William Wilson vê-se atormentada por um ser idêntico a si, que compartilha sua corporeidade ao mesmo tempo em que aquela estranha a familiaridade que nutre com seu sósia. Rememorando-se o desfecho, o espelho favorece a ambiguidade e, simultaneamente, realiza a confusão visual, bem como narrativa, dupla entre a personagem principal e a entidade que partilha seu nome.

Dito isso, o presente texto tem como norte verificar como o Complexo de William Wilson é reconfigurado em $O$ médico e $o$ monstro $^{2}$ (Strange Case of Dr. Jekyll and Mr. Hyde, 1886), sob a pluma de Robert Louis Stevenson. Pretende-se notar como o cerne e estrutura desse Complexo modificam-se ao ponto de constituir uma revisão, ampliação e inovação de seus princípios fundamentais; como o motivo do duplo, na narrativa mencionada, é distorcido e transformado de modo a subverter a ordem do signo dos dois. Para tanto, embasam as considerações que seguem o conceito clássico

2 Apesar de já existirem traduções do romance de Stevenson com um título mais adequado ao original em inglês ( $O$ estranho caso do Dr. Jekyll e Mr. Hyde na tradução de Braulio Travares. Vide Referências), preferiu-se manter o título que fora, primeiramente, introduzido ao português. Tal preferência não configura um menosprezo pela nova versão em língua portuguesa do título do romance em questão, somente uma opção pelo título mais conhecido no meio acadêmico. 
de duplo desenvolvido por Rank, bem como os ensaios que versam sobre a questão do espelho de Umberto Eco e de Jacques Lacan e as considerações de Jacques Derrida acerca do quase conceito de phármakon. Além disso, no que concerne à literatura gótica, Fred Botting amparará teórica e criticamente nossas discussões sobre essa vertente literária.

Assim, as linhas que seguem objetivam articular a transformação do Complexo de William Wilson a partir do romance de Stevenson mencionado, seus novos ares, sua paleta de cores renovada e seus relevos metamorfoseados.

\section{JEKYLL E HYDE: ALQUIMIA E FEITIÇARIA ${ }^{3}$}

Na pauta da primeira edição do livro Gothic (1996), de Fred Botting, nota-se como as nuances e contornos de dois termos dão início às discussões do teórico inglês: horror e terror encontram sua anatomia dissecada nas linhas do primeiro capítulo. Enquanto horror configura cenas e imagens de gangrenas, mortes macabras, monstros e bestas, produzindo um resultado estético abjeto em sua constituição imagética, o terror mantém-se no campo do Unheimliche $^{4}$, do inconsciente, do pertencente inteiramente à psique, delimitando aquilo que é desconhecido e terrificante à estrutura empírica da realidade, os cantos obscuros da mente que se contrapõem à racionalidade lógica. Com esse postulado, Botting

3 Uma versão resumida da presente seção consta nos Anais do CENA IV - Colóquio de Estudos em Narrativa: A ficcionalização do medo na narrativa.

4 Devido ao fato dos termos Unheimliche e unheimlich (em alemão, substantivo e adjetivo, respectivamente) abarcarem uma alta carga de significado, como apresenta Freud no começo de seu ensaio, preferiu-se adotar os termos no idioma original, uma vez que as palavras geralmente utilizadas em português para traduzi-lo, estranho e inquietante, não comportam a indecidibilidade do termo (familiar e não-familiar) em seu idioma original. 
proclama que "O Gótico pode talvez ser chamado a única verdadeira tradição literária. Ou sua mancha" (1996, p.16)

No começo do fio narrativo de $O$ médico e o monstro, o horror plasma-se no olhar da personagem Gabriel John Utterson, que se vê na tentativa de nomear as características do famigerado Edward Hyde, cuja aparência dana sua fala, bem como a de seu parente Enfield:

Mas havia um aspecto curioso. Eu tinha sentido uma vívida repugnância por aquele homem assim que pus os olhos nele [...].

- Não é fácil descrevê-lo. Há algo de errado com sua aparência; alguma coisa incômoda, alguma coisa profundamente detestável. Nunca vi um homem que me desagradasse tanto e, no entanto, não sei dizer o porquê. Ele deve sofrer algum tipo de deformação; a impressão que nos dá é de algo disforme, embora eu não consiga dizer especificamente em que aspecto. É um homem de aparência extraordinária, mas de fato eu não posso apontar nada que seja fora do comum. Não, cavalheiro, descrevê-lo está além de minha capacidade. E não é por esquecimento, porque afirmo que neste instante consigo vê-lo com toda clareza. (STEVENSON, 2011, p.20; 23-24 - grifo nosso)

Dissecando-se a identidade do advogado e amigo de Jekyll, vêse como o dom da pronúncia não está somente nas características retóricas de sua profissão, mas em seu próprio ser: o nome Utterson (utter+son) indiciaria, em inglês, o descendente do proferir (utter = proferir; son = filho, descendente), o filho do portador da fala e do absoluto (outro significado possível para utter). Tendo em

5 No original: "Gothic can perhaps be called the only true literary tradition. Or its stain". Todas as citações deste livro de Fred Botting foram traduzidas pelos autores do presente artigo. 
mente essa característica, aquele que realiza a fala absoluta, John Utterson, revela-se $o$ detetive dessa narrativa, o que se encarregará de investigar os mistérios acerca da vida do cientista e médico. Nota-se seu comprometimento com a profissão do investigar, ao proferir seu ultimato detetivesco: "'Se ele é Mr. Hyde' - pensava ele -, 'eu serei Mr. Seek ${ }^{6 \prime \prime \prime}$ (STEVENSON, 2011, p.29).

Ao tentar descrever a imagem distorcida daquele que se ocuparia de um assassinato mais tarde, Utterson, juntamente das demais personagens que também se ocupam desse ato, frustram-se, já que impedidos da pronúncia daquilo que levaria ao reconhecimento: o estabelecimento da identidade, aquilo que é próprio de um eu. Mesmo aquele impregnado pelo dom da pronúncia absoluta não atingiria o feito de identificar Hyde pela sua aparência, atendo-se somente a uma tentativa falhada: a "falta de humanidade" será uma das expressões que permeará o discurso de todas as personagens que vislumbrarão o ser de Hyde. Utterson é um dos que se deparam com esse obstáculo intransponível:

Era de estatura pequena, bem vestido, e sua aparência, mesmo a certa distância, produziu uma impressão de aversão no homem que o observava.

[...] Mr. Hyde era pálido e com aparência de anão; dava uma impressão de deformidade sem que houvesse nele nenhuma má-formação visível, tinha um sorriso desagradável, tinha sabido se impor ao advogado com uma mistura ameaçadora de timidez e ousadia, e falava com uma voz enrouquecida, sussurrante e meio alquebrada;

60 trocadilho com os nomes Hyde e Seek refere-se à brincadeira Hide and Seek, no Brasil chamada "esconde-esconde", jogo no qual um se esconde (hide) e ao outro cumpre a tarefa da procura (seek). Esse procurar e esconder conduz a narrativa em questão, impregnando inclusive o nome do personagem teratológico, Hyde, o oculto. 
todos estes pontos se somavam a seu desfavor, mas nem mesmo todos eles juntos podiam explicar a sensação de repulsa, nojo e medo experimentada por Mr. Utterson. "Deve haver alguma outra coisa", pensava o perplexo cavalheiro, "Existe algo mais, e gostaria de dar um nome a isso. Deus me perdoe, o indivíduo mal parecia humano! Tinha algo de troglodita, será? Ou será como na antiga história do Dr. Fell? Ou ainda a simples irradiação de uma alma maligna, que transpira através do barro que a hospeda, e o transfigura? Penso que seja esta última hipótese, porque, oh, meu pobre amigo Henry Jekyll, se alguma vez eu enxerguei a assinatura de Satã sobre um rosto, foi o desse seu novo amigo". (STEVENSON, 2011, p.30; 31-32)

Considerando a relação de oposição e hierarquia presente na sociedade vitoriana, ambientação esta que se percebe na narrativa em questão, bem como a destacada inumanidade de Hyde, este poderia ser entendido como um alien nas duas acepções em inglês: o estrangeiro, o estranho, aquele não aceito pela sociedade, ostracizado por um estigma social - o entendimento do termo entre os vitorianos -; e também o alienígena, o extraterrestre, aquele que transcende ao entendimento de humano, cujas características não se assemelham ao que se prevê na biologia e na imagética da espécie humana. A aparência de Hyde estaria condicionada a essa mancha estrangeira, o que inferioriza e denigre a sociedade, sendo os termos mancha, inferioriza e denigre concepções inerentes à mentalidade vitoriana, calcada em ideias rígidas e preconceituosas, além daquilo que é novo, o diferente por oposição ao que é familiar, diferente que, para os vitorianos, é absolutamente indesejado por trazer implícito em si mesmo o questionamento do status quo sócio-cultural. 
Ante essas reflexões, observa-se como, na figura de Edward Hyde, está plasmado o Unheimliche: todos os que experimentam a visada em Hyde (e de Hyde), somente visualizam o desprovimento de humanidade, não conseguindo fixar uma especificidade ou uma semelhança em relação ao humano que possa caracterizar essa personagem. De certa maneira, eles veem o Unheimliche - que, por limitar-se ao psíquico, não deveria ser visível -, aquilo que lhes é estrangeiro, mas também enxergam o familiar ao estabelecer o conceito de humanidade como referente para definir o inumano. Nas palavras do cunhador do termo, o Unheimliche constitui-se como "[...] aquela categoria do assustador que remete ao que é conhecido, de velho, e há muito familiar" (FREUD, 1996, p.238).

Logo, o corpo do protégé de Henry Jekyll disponibilizaria de dois mecanismos de ocultação: a impossibilidade da identificação (a atribuição de um traço que tornaria viável o desenhar de uma identidade), bem como umestranhamento profundo, desencadeado, segundo a perspectiva do outro, pela sua inumanidade. Desse modo, Hyde conjuraria um feitiço de ocultação sobre si próprio, um conjuro que limitaria ou repeliria a incidência racionalizante característica da realidade empírica (a experiência do cognoscível) e, consequentemente, esgarçaria as leis que governam seu tecido. Ao performar esse encantamento, sua circulação pelas ruas de Londres, além de seu acesso à casa de Jekyll, estariam garantidos por um invólucro protetor.

Até o oitavo episódio da narrativa, essa atmosfera ambígua instalada pelo prolongamento de um segredo, atmosfera que se pode entender de terror, perpetua-se, sendo somente nos dois últimos capítulos que o mistério rondando Jekyll e Hyde dissolve-se. Por meio 
da narrativa do Dr. Hastie Lanyon e a confissão do Dr. Henry Jekyll, o advogado-detetive Gabriel Utterson lê a narrativa do fato, que permitiria a compreensão da relação entre o cientista e sua forma teratológica: ao ingerir certa substância química, produto de um projeto de Medicina transcendental, Jekyllatingira uma transformação capaz de alterar seu corpo e mente, metamorfoseando-o em Edward Hyde, o assassino estranho e repulsivo: "E quis a sorte que o rumo dos meus estudos científicos, dirigidos para tudo que é místico e transcendental, acabasse lançando uma poderosa luz nesta minha consciência sobre a eterna guerra entre os elementos que me compõem" (STEVENSON, 2011, p.86). É por meio desses dois textos, a narrativa e a confissão, que, assim como o Gótico rompe as barreiras do real, "Transgredindo as amarras da realidade e do possível, elas [as produções góticas] também desafiaram a razão pela sua desmedida aceitação de ideias fantasiosas e voos imaginários" (BOTTING, 1996, p.6) ${ }^{7}$, as paredes impostas pelos capítulos anteriores são quebradas e tem lugar o horror.

Para notar o que implica tais eventos, é preciso tomar, primeiramente, o caminho do texto de Lanyon. Neste, o doutor explica os eventos rondando a figura enigmática e repulsiva de Edward Hyde. Ao receber uma carta de seu antigo amigo Jekyll, com o qual tivera uma rusga a respeito de um projeto, evitando contato desde então, na qual explicitava procedimentos rígidos que concerniam uma gaveta contendo certas substâncias e sais, Lanyon recebe a visita do inumano, que refuta a posição inicial do médico sobre o projeto transcendental de seu colega de Medicina:

7 No original: "Transgressing the bounds of reality and possibility, they [Gothic productions] also challenged reason through their overindulgence in fanciful ideas and imaginative flights." 
- Então muito bem - disse meu visitante. Lanyon, lembre-se do seu juramento: o que vai acontecer agora está protegido pelo segredo de nossa profissão. E agora, você, que sempre foi apegado a uma visão do tipo mais estreito e materialista, você que negava as virtudes da medicina transcendental, você que sempre zombou dos que lhe eram superiores... contemple! (STEVENSON, 2011, p.83)

Instalado pelas palavras ameaçadoras de Hyde que, a seguir, ingere o preparado, o horror toma as próprias feições de Lanyon, assim como em suas palavras:

Ele pôs o frasco nos lábios e sorveu seu conteúdo com um único gole. Ouviu-se um grito; o homem oscilou, cambaleou, e agarrou-se à mesa para manter-se de pé, olhando-me com olhos esbugalhados, e a boca aberta, arquejante; e enquanto eu o observava julguei perceber uma mudança - ele pareceu inchar - seu rosto escureceu e suas feições pareceram derreter-se, alterar-se, e no momento seguinte eu tinha ficado de pé e dado um pulo para trás, de encontro à parede, com os braços erguidos para me proteger daquele prodígio, e minha mente engolfada pelo terror.

- Oh meu Deus! - gritei, e outra vez, e mais outra; porque ali, diante dos meus olhos, pálido e trêmulo, quase desmaiado, e tateando diante de si com mãos incertas, como um homem arrancado à morte, ali estava Henry Jekyll! (STEVENSON, 2011, p.83)

A experiência com a transformação - na verdade, com o estar presente à transformação, com o in præsentia da metamorfose afeta não somente as emoções, mas também o corpo de Lanyon, 
que recebe, por meio da alta gama imagética do horror, a irradiação mortífera do terror. In præesentia à metamorfose, Lanyon sofre outro aspecto do feitiço de Hyde, agora na sua potência máxima: com o segredo revelado, o mecanismo de proteção, desencadeado pela ação química, libera a infecção do Unheimliche no ser observador, transmitindo a contaminação unheimlich, cujo produto revelara-se previamente à leitura da narrativa por Utterson: a morte de Hastie Lanyon. O conjuro de Hyde alcança a relação perfeita com o outro: a conexão pela irradiação do Unheimliche com uma alteridade diferente, resultando, paradoxalmente, no findar da sua existência material. A contaminação mortal é revelada como o terceiro efeito do encantamento do inumano; eventualmente, isso denuncia a (id)entidade em questão como um necromante, aquele com o conhecimento dos arcanos do mundo inferior. O próprio Jekyll afirma a invocação de Hyde de um universo inferior, escondido num canto de sua alma:

Este espírito sobrenatural que eu invocara do interior de minha própria alma, e deixara à solta no mundo para ir em busca de seus prazeres, era um ser inerentemente maligno e vil; bebia o prazer com avidez bestial ao contemplar as torturas infligidas a outrem; implacável como uma estátua de pedra. (STEVENSON, 2011, p.92)

O incrustamento do Unheimliche na figura de Edward Hyde arquiteta a revisão, inovação e ampliação do segundo elemento do Complexo de William Wilson outrora listado: o Unheimliche irradia da figura de Hyde, atinge seus espectadores com o horror e espanto, mas inova com as novas possibilidades desse fator. Seus observadores não atingem o processo de identificação de 
Hyde pela linguagem, pois uma alta carga imagética provém dessa personagem, a qual é atribuída, pelos que a observam e pelos próprios leitores, a um caráter genérico de inumanidade, e o resultado da observação da transformação inerente ao corpo do outrora Jekyll, momento este em que o Unheimliche atinge seu ápice, é a morte do observador, como se olhar o processo alquímico da transformação de Jekyll em Hyde, e vice-versa, fosse o mesmo que olhar para a Medusa, o que implica um laivo de Complexo de Édipo na tessitura da obra de Stevenson.

O conjunto desses três fatores até aqui discutidos - a impossibilidade de identificação, o estranhamento perante a inumanidade e o olhar medusino - configura em torno de Hyde uma espécie de mecanismo de proteção contra seus observadores à medida que desloca, desvia, desfoca a luz que possibilitaria a visibilidade da sua figura, tornando-a borrada, quase indescritivel, protegida, como diriam os físicos, por uma espécie de escudo de paralaxe ${ }^{8}$, o que lhe confere algo de alienígena, afirmado na confissão, presente no último capítulo, assinada por Jekyll, sua contraparte científica:

[...] e, arrebatado de esperanças e triunfo, arrisquei-me a ir, na minha nova forma, até o meu quarto de dormir. Cruzei o pátio, sob o olhar das constelações, e pensei, com espanto, que eu era a primeira criatura desta espécie que elas chegaram a contemplar em sua vigília insone; entrei furtivamente pelos corredores, um estranho 8 Paralaxe constitui, segundo a Física, o fenômeno ótico de desvio da luz quando observada a grandes distâncias. Segundo o Dicionário UNESP do português contemporâneo, "1 aparente deslocamento de um objeto com a mudança do ponto de observação. 2 aparente deslocamento angular de um corpo celeste devido ao fato de a observação se fazer a partir da superfície e não do centro da Terra, ou a partir da Terra e não do Sol" (BORBA, 2004, p.1025). 
em minha própria casa, e chegando ao quarto vi pela primeira vez a aparência de Edward Hyde. (STEVENSON, 2011, p.89-grifo nosso)

Esse conjunto idiossincrático assumiria também um gênero de feitiço, o encanto mortal do necromante assassino, presente na aura maligna de Hyde, sublinhada em vários momentos da obra como, por exemplo, quando Lanyon o vê pela primeira vez em seu consultório:

[...] e quando o acompanhei até o meu consultório, que estava com todas as luzes acesas, mantive minha mão na arma, dentro do bolso. Lá dentro, pelo menos, tive a possibilidade de examiná-lo melhor. Nunca o vira antes, disso tive certeza. Era um homem pequeno, como já falei; tive um outro choque ao observar a expressão do seu rosto, que tinha uma notável combinação de grande atividade muscular e uma aparente debilidade de constituição; e, por último, mas não o menos importante, percebi o estranho desconforto intimo que me produzia a sua proximidade. Esse desconforto assemelhava-se um pouco a uma rigidez muscular, e era acompanhado por uma desaceleração do pulso. Naquela hora, eu o atribuí a algum tipo de aversão instintiva e pessoal, e me admirei apenas diante da intensidade dos sintomas; mas desde então tive motivos para crer que as causas estão localizadas em algo mais profundo na natureza humana, e estão ligadas a um aspecto mais nobre do que a mera noção de ódio.

[...] Na verdade, uma vez que existia algo de anormal e desabonador na própria essência da criatura que agora me encarava, algo que me invadia, me assustava e me provocava revolta, aquela disparidade imprevista parecia se encaixar nessa impressão e reforçá-la; e assim somava-se, ao meu interesse quanto à natureza e ao caráter 
daquele indivíduo, uma curiosidade quanto à sua origem, sua vida, suas posses e sua situação social. (STEVENSON, 2011, p.80-81 - grifo nosso)

Quanto à confissão de Henry Jekyll, percebe-se a existência de três vozes: a voz narrativa sendo composta pela identidade "Henry Jekyll" e suas experiências; as emoções e vivências quando a voz "Edward Hyde" guia o corpo que hospeda a ambas identidades, e uma terceira voz, afastada do dilema dual Jekyll-Hyde (que será abordada na próxima seção do presente estudo). Esse fenômeno trinitário é observável na tessitura textual do romance, por exemplo, pelo uso da terceira pessoa narrativa como referência a Jekyll e Hyde:

Daí, creio eu, o fato de que Edward Hyde era bastante menor, mais leve e mais jovem do que Henry Jekyll [...].

Hyde cantarolava uma canção quando preparou a poção transformadora e, quando a bebeu, brindou ao homem que acabara de matar. As dores da transformação mal tinham acabado de flagelar seu corpo quando Henry Jekyll, com o rosto banhado em lágrimas de gratidão e remorso, caía de joelhos e erguia as mãos para Deus. O seu véu de autocomplacência tinha sido rasgado de cima abaixo. (STEVENSON, 2011, p.89; 97)

Segundo seu próprio discurso, Henry Jekyll, devido à superficialidade social da sua aparência, teria imposto a dissociação ao seu corpo:

E no entanto o meu defeito mais grave era uma certa impaciência para desfrutar os prazeres da vida, algo que trouxe a felicidade a muitos, mas que me foi difícil conciliar com minha firme vontade de caminhar de cabeça erguida e de apresentar 
ao mundo uma imagem mais respeitável que a da maioria dos homens. $\mathrm{O}$ que resultou disto foi que passei a dissimular esses meus prazeres; e quando cheguei à idade da razão e comecei a olhar em torno e avaliar meu progresso e minha posição no mundo, já estava há muito comprometido com essa minha profunda duplicidade íntima. Muitos homens poderiam até vangloriar-se dessas irregularidades das quais eu me sentia culpado, mas, em função dos altos parâmetros que eu tinha estabelecido para mim mesmo, tive que encará-los e escondê-los com uma sensação quase mórbida de vergonha. Foi, portanto, a natureza exigente das minhas aspirações, mais do que qualquer degradação específica decorrente dos meus defeitos, que me fez ser aquilo em que me tornei, e, criando uma divisão ainda mais profunda do que na maioria dos homens, afastou de mim a parte sã e a parte doentia que dividem e formam a natureza dual do ser humano. (STEVENSON, 2011, p.85)

Isso estabeleceria, segundo o médico, a dualidade numa só identidade: "[...] eu não era mais eu mesmo quando abandonava o autocontrole e me entregava à depravação do que quando trabalhava, à luz do dia, para aumentar o conhecimento humano ou para aliviar a dor e o sofrimento alheios" (STEVENSON, 2011, p.86). Logo, o duplo não se instala com a emergência de Hyde, mas pela prática do cientista em se deixar guiar pelas aparências, separando a esfera da respeitabilidade social de sua senda de prazeres. Destarte, Hyde compartilharia com Jekyll a ambição pela jovialidade libertina e boêmia, os prazeres que a alta sociedade vitoriana condena: "Jekyll (que era uma personalidade mista) ora demonstrava sensibilidade e apreensão, ora um prazer ávido em se projetar nos prazeres e aventuras de Hyde [...]" (STEVENSON, 2011, p.95). 
Com a ingestão do produto de seu projeto místico e transcendentalista, Edward Hyde emerge em Henry Jekyll a partir de um processo de dissociação que não previa uma total cisão. Jekyll usufrui dos prazeres permitidos e desfrutados por Hyde, além de compartilhar certas memórias com o assassino e mesmo ouvi-lo como uma voz outra: “E, também, que esse horror insubordinado [...] estivesse encarcerado em sua própria carne, onde ele podia ouvi-lo a murmurar em sua luta incessante para vir à luz [...]". (STEVENSON, 2011, p.103).

Ainda na confissão de Jekyll, menciona-se um momento no qual Hyde, nos primeiros instantes de seu existir, contempla-se em frente a um espelho. Como afirma Jacques Lacan em seu ensaio "O estádio do espelho como formador da função do eu" ("Le stade du miroir comme formateur de la fonction du je", 1949), a criança (em nosso caso, um ser adulto nos primeiros momentos de existência), por meio da experiência com o outro (a imagem refletida - tida nesse momento como um outro - como também o refletir de si na imagem dos outros), estabelece seu eu, o que se caracteriza por

[...] uma série de gestos em que ela [a criança] experimenta ludicamente a relação dos movimentos assumidos pela imagem com seu meio refletido, e desse complexo virtual com a realidade que ele reduplica, isto é, com seu próprio corpo e com as pessoas, ou seja, os objetos que estejam em suas imediações. (LACAN, 1998, p.96-97)

Assim, Hyde desenvolve seu eu através de seu reflexo, cuja imagem já está impregnada pelo fator Unheimliche. Ao adotar sua identidade, ele passa a portar em sua mente não só seu Ich ("eu"), mas também estariam impregnados em seu cerne o Unheimliche 
e as reminiscências mentais de Jekyll. Conforme Umberto Eco em seu ensaio "Sobre os espelhos" ("Sugli specchi", 1985), a superfície catóptrica é "[...] uma prótese absolutamente neutra, e permite que se obtenha o estímulo visual onde o olho não poderia alcançar [...]. Como prótese, os espelhos são canais. Um canal é cada medium material que permite a passagem de informação [...]" (1989, p.18 grifo do autor). Logo, a aura unheimlich, o escudo de paralaxe que garante a Hyde seu invólucro protetor e a eficiência de seu feitiço, advém de sua própria figura: ela reflete no espelho e, pela imagem neste originada, a identidade hydeana articula sua personalidade, a qual, mais tarde, adquire a habilidade de usufruir dos prazeres mundanos e de levar à morte todo aquele que contemple o momento de sua transformação no tecido narrativo. Consequentemente, sua manifestação é adjetivada, por várias personagens, como um irradiador de malignidade. Edward Hyde, por meio do universo catóptrico, vislumbra "[...] uma realidade capaz de dar a impressão da virtualidade" (ECO, 1989, p.37), ou seja, uma realidade protegida por sua própria mímesis. Ele se torna quem é com a impressão representacional do real. De certa maneira, o inumano, a manifestação teratológica da alteridade de Jekyll, tem sua síntese vivenciando a ficção em meio a um universo ficcional; a mímese recostura, dessa forma, seu tecido na plena realidade narrativa.

Além dos poderes intrínsecos em seu ser, Edward Hyde, com sucessivas transformações, amadurece na sua constituição física e mental, passando por uma espécie de crescimento. Com a recorrência quase incessante das transformações, Henry percebe que Edward está crescendo, como também adquirindo poder sobre o corpo que abarca as duas personalidades: 
[...] parecia-me ultimamente que o corpo de Edward Hyde tinha crescido em estatura, como se (quando eu assumia sua forma) eu sentisse nele uma energia acima do normal; e passei então a entrever o risco de que, caso isto se prolongasse, o equilíbrio da minha natureza fosse permanentemente comprometido, meu poder de metamorfose voluntária ficasse ameaçado, e a pessoa de Edward Hyde viesse a predominar. (STEVENSON, 2011, p.94-95)

Acerca disso, pode-se notar que o primeiro braço do Complexo de William Wilson (a existência de uma segunda entidade, compartilhando traços físicos e certos detalhes psíquicos da personalidade "original") é totalmente revisto e passa por um crivo inovador e ampliador: não há mais um outro ser no exterior, mas sim no interior corpóreo do eu. O Doppelgänger não mais caminha pela exterioridade, mas compartilha processos mentais com seu "eu original". Enquanto, no referido Complexo, a psicanálise prevê a somatização para o exterior "real", seja esse real o empírico ou o ficcional, no romance de Stevenson o desdobramento de personalidade, seja ele devido a uma possível esquizofrenia ou a um Transtorno Dissociativo de Identidade (TDI) ou ainda a um amálgama dos dois, somatiza-se para o interior do corpo, além de configurar uma transformação física completa. Segundo a Biologia, há aí um processo de reestruturação genética: o DNA de Henry Jekyll passa por uma reorganização total, ao ponto de influenciar inclusive sua mentalidade, em um processo semelhante ao que ocorre em boa parte da ficção sobre alienígenas.

Contudo, falta um elemento para a completude dessa primeira parte do quebra-cabeça: a substância química resultante da mente genial de Henry Jekyll. Desde o início de seus estudos científicos, ares 
místicos e transcendentais circulam seus interesses, culminando na droga transformadora:

Comecei a perceber, mais profundamente do que alguém jamais afirmou fazê-lo, a trêmula imaterialidade, a transitoriedade de névoa deste corpo aparentemente tão sólido que nos serve de vestimenta. Descobri certos agentes químicos capazes de abalar e arrancar das raízes esta nossa roupagem de carne e osso, tal como uma ventania arrebata uma tenda. (STEVENSON, 2011, p.87)

Apesar da ânsia pelo conhecimento do pesquisador, há a instalação do hesitar em seu discurso. Mesmo assim, ele ingere o líquido que mais tarde o conduz à escrita do "seu" documento final:

Hesitei muito antes de submeter minha teoria ao teste da prática. Sabia que estava correndo um perigo mortal; porque qualquer droga capaz de controlar e abalar de forma tão violenta a própria fortaleza da nossa identidade, poderia, por alguma mínima diferença, produzir uma overdose, ou, por qualquer inadequação no momento da experiência, destruir por completo o tabernáculo imaterial que era meu propósito alterar. Eu já havia há muito tempo preparado a minha tintura; comprei de uma vez só, a uma empresa de ingredientes químicos por atacado, uma grande quantidade de um sal específico que eu sabia, pelas minhas experiências, ser o último ingrediente necessário; e, na madrugada de uma noite para sempre maldita, misturei esses elementos, vi-os fervilhar e fumaçar juntos no frasco, e, quando a ebulição amainou, com um estranho impulso de coragem bebi toda a poção.

Seguiram-se as dores mais excruciantes, um rangido nos ossos, uma náusea mortal, e na minha alma um horror que não pode ser excedido, seja 
no instante do nascimento ou no da morte. Aos poucos essas agonias foram se atenuando, e voltei a mim, como quem desperta de uma grave doença. Havia algo de estranho nas minhas sensações, algo indescritivelmente novo e, por sua própria novidade, incrivelmente prazeroso. (STEVENSON, 2011, p.87-88 - grifo nosso)

Algo estranho se perpetua nas extremidades corporais de Jekyll. O Unheimliche começa a agir nas suas veias e Edward Hyde vem à tona. Assim, pode-se dizer que a mistura descoberta, os passos científicos, (al)químicos, dão luz a Hyde, luz que imediatamente se transforma em sombra com o simples ato do seu manifestar. Henry Jekyll cria a vida em si mesmo, lança a animação no seu corpo já animado e cindido e sua criação entra num voo independente. Em outras palavras, Jekyll, revelando-se um alquimista no século da Química, inventa o elixir da vida, aquilo que constitui o supremo desejo do humano: a imortalidade. Apesar do inumano desenvolver-se num caminho alienígena e necromântico, o intento primal da experiência do alquimista permanece na perpetuação do viver - Jekyll adquire o fardo divino; como um Frankenstein ético e moralmente correto, justamente o que o cientista de Mary Shelley não é, Jekyll se torna responsável pelo emergir de Edward Hyde, sua criação: "Jekyll tinha mais do que as preocupações de um pai; Hyde tinha menos que a indiferença de um filho" (STEVENSON, 2011, p.95). Seu elixir da vida, portanto, revela-se, como ocorre em toda a tradição desse tema literário, incompleto ou um elixir que causa a morte.

Ao longo do texto de Lanyon e da confissão presentes no final do romance, percebe-se que a primeira ingestão da droga é responsável pelo aparecimento do assassino. Com o passar do 
tempo, a indução da transformação torna-se mais difícil, sendo necessária uma dose maior, segundo a mente de Jekyll:

O poder da droga não tinha se manifestado sempre com a mesma intensidade. Uma vez, bem cedo na história das minhas experiências, tinha me falhado por completo; desde então eu fora forçado, mais de uma vez, a duplicar, e uma vez, com enorme risco de vida, a triplicar sua quantidade; e essas incertezas tinham projetado a única sombra que pairava sobre minha satisfação. (STEVENSON, 2011, p.95)

Além da resistência à droga, a transformação não mais gerava, com o uso prolongado, as dores excruciantes, "Mas quando adormecia, ou quando a droga deixava de produzir efeito, eu me via, quase sem transição (porque as dores da transformação diminuíam dia a dia) [...]" (STEVENSON, 2011, p.103). Assim, depreende-se que num primeiro instante, isto é, no primeiro ciclo da droga, Hyde está condicionado à substância, mas o seu uso contínuo garante o chegar de um segundo momento: as transformações por indução são mais difíceis, sendo necessárias doses duplas ou triplas, como também um efeito colateral torna-se ativo, qual seja o estado de Hyde naturaliza-se, inscreve-se, na carne do corpo - consequentemente, da mente e do espírito - e suas vezes no leme dão-se mais frequentemente. Essa anomalia ocorre quando o efeito da droga cessa ou quando Jekyll está nos domínios de Morfeu:

[...] e, saltando da cama, corri para diante do espelho. Diante da imagem que surgiu a meus olhos, meu sangue transformou-se em alguma outra coisa, rala e gélida. Sim, eu tinha ido para a cama como Henry Jekyll, e tinha acordado como Edward Hyde. Como se explica isso?, foi o que me perguntei; e 
depois, com outro sobressalto de terror: Como isto pode ser remediado? (STEVENSON, 2011, p.93-94)

Com o vício desenvolvido, Jekyll tenta combatê-lo com o próprio vício, porém falha:

Imagino que, quando um ébrio medita consigo mesmo sobre o seu vício, talvez uma vez entre quinhentas ele tenha consciência dos perigos a que se expõe através de sua brutal insensibilidade física [...]. Meu demônio tinha sido encarcerado por muito tempo, e emergiu rugindo [...]. Mas eu me despira voluntariamente de todos aqueles instintos de equilíbrio com que mesmo os piores dentre nós continuam a caminhar com firmeza mesmo cercados de tentações; e no meu caso, ser tentado, ainda que da forma mais leve, era sinônimo de cair. (STEVENSON, 2011,96-97)

Nesse segundo ciclo, ingerir a droga bastaria para que Jekyll voltasse ao controle do que fora incitado, possibilitado, pela própria droga. Há aqui um jogo que se configura não em termos de veneno-remédio, mas de veneno-veneno: um veneno para combater outro veneno.

A partir daí, um terceiro momento instala-se: o vício é incontrolável; os episódios premonitórios de Hyde somente são controlados pela administração de altas doses da droga e a tentativa de estocá-la não se torna possível: "Em resumo: daquele dia em diante foi apenas com um esforço digno de um ginasta, e somente com a aplicação imediata da droga, que pude retornar à aparência física de Jekyll" (STEVENSON, 2011, p.102), porém, não se deve perder de vista que foi para trazer Hyde à tona que Jekyll inventou e ingeriu sua droga. Os sais mais puros não mais atingem 
o resultado desejado. Jekyll conclui que fora uma determinada impureza a responsável pelo (in)sucesso de seu experimento. Por meio do impuro, o âmago da psique, em ambos os sentidos do termo, o psicanalítico e o grego, no qual, em junção com o termo pneuma, equivale ao entendimento ocidental de alma, é tocado: "[...] e agora estou persuadido de que era a minha primeira amostra que era impura, e que foi esta impureza desconhecida que resultou na eficácia da fórmula". (STEVENSON, 2011, p.104). Note-se que é uma impureza que permite a eficácia da substância.

Portanto, os dois primeiros elementos do Complexo de William Wilson são inovados: não há mais "um e um" no tecido da realidade narrativa, mas um amálgama de duas personalidades numa mesma corporeidade. Tal corpo transmuta-se ao manuseio de uma fórmula química, cuja eficácia encontra seu princípio ativo numa impureza rara. Já o segundo elemento, o Unheimliche, presentifica-se num outro design: Hyde, com sua aparência repulsiva, protegese e enfeitiça o(s) outro(s) por meio de uma aura unheimlich, um invólucro e um conjuro capazes de lhe garantir a fruição dos desejos e prazeres que o mundo tem a lhe oferecer. Nessa perspectiva, o próprio sentido freudiano de Unheimliche parece ser inovado, já que ganha um aspecto de libertação dentro de um ideário que se poderia dizer romântico, além de uma materialidade não prevista pelo Médico de Viena. O Unheimliche, tradicionalmente tomado, pelas teorias do gótico, do fantástico e do insólito, como sinônimo de duplo, torna-se um modo de transcendência libertadora, quase uma paradoxal epifania, cujo resultado ou efeito colateral não é nem o libertar de Hyde por meio de uma droga, nem o voltar a ser Jekyll por meio da mesma droga, mas o descolamento de um 
terceiro ser a partir da transiência e transitoriedade entre essas duas identidades, o vir a ser de algo Outro (um outro de outros) que não se prende ao campo metafísico (mente, espírito, psique etc.), mas se manifesta no físico como fisicalidade $e$ textualidade, como fisicalidade na textualidade, como fisicalidade $d a$ textualidade, a existência de uma nova entidade, que perambula imperceptível ao longo das (entre)linhas da narrativa do médico e do monstro, porém mais presente do que os próprios médico e monstro.

\section{A INSURGÊNCIA DO PARADOXO JEKYLL-HYDE}

Com as idas e vindas do cientista e do assassino, um terceiro ser emerge: o hospedeiro das duas personagens, que se adapta física e mentalmente à personalidade que no momento está consciente. Em outras palavras, a droga não origina apenas Edward Hyde, mas sintetiza também o corpo do velho Jekyll (aparentemente uno) num envelope portador de dois seres que, diferentemente do previsto na tradição do duplo, não são opostos, mas sim complementares. 0 que se observa nesse estranho caso é a insurgência da fragmentação, não mais um caso exclusivamente de duplicação, e sim de triplicação. O trio-protagonista sofreria as diversas mutações ocasionadas pela primeira alternação, variando de Jekyll a Hyde, de Hyde a Jekyll, ao ponto de sofrer uma conjunção. Isso se evidencia pela impossibilidade de afirmar que a confissão presente ao fim do romance seja de autoria de Henry Jekyll, ou de Edward Hyde ou ainda da Criatura (o hospedeiro), uma vez que, em vários instantes desse texto composto, a princípio, a seis mãos, o eu varia de personalidade:

Nasci no ano de 18..., numa família de grande fortuna, dotado de talentos consideráveis, com uma tendência natural para o trabalho, afeiçoado ao respeito dos 
meus concidadãos mais sábios e de melhor caráter, e deste modo, como é fácil supor, com todas as garantias de um futuro honrado e brilhante.

[...] Não pretendo descrever em detalhes as infâmias das quais fui cúmplice (porque mesmo agora é-me difícil admitir que as cometi eu mesmo); quero apenas indicar os avisos e os sucessivos passos com que meu castigo foi se aproximando aos poucos. Tive um acidente que mencionarei apenas de passagem, pois não trouxe outras consequências. Um ato de crueldade contra uma criança atraiu sobre mim a ira de um transeunte, um homem que reconheci, dias atrás, na pessoa de um parente seu [...].

[...] Senti que teria agora de escolher entre elas. Minhas duas naturezas tinham uma memória em comum, mas todas as outras faculdades eram compartilhadas entre elas de forma desigual.

[...] No dia seguinte, os jornais revelaram que o crime fora presenciado por uma testemunha, que a culpa de Hyde era conhecida por todos, e que a vítima era um homem público altamente considerado. Não tinha sido apenas um crime, mas uma trágica imprudência. Acho que fiquei contente em saber disto; alegrei-me de ter os meus melhores impulsos a salvo, protegidos pelo medo do cadafalso. Jekyll era agora minha cidadela de refúgio, porque se Hyde entremostrasse seu rosto por um só instante as mãos de todos os homens estavam prontas para agarrá-lo e fazer-Ihe justiça. (STEVENSON, 2011, p.85; 92; 95; 98 - grifo nosso)

Dessa forma, tais indícios textuais evidenciam que esse eu pluraliza-se pelas várias faces que se presentificam ao longo da escrita da confissão: em alguns momentos Henry Jekyll, focando na sua experiência existencial, está no controle da narração 
confessional - "Nasci no ano de 18..., numa família de grande fortuna, dotado de talentos consideráveis, com uma tendência natural para o trabalho [...]" -; noutros Edward Hyde toma a posse da caneta, relembrando seus atos transgressores - "Um ato de crueldade contra uma criança atraiu sobre mim a ira de um transeunte $[. . .]^{\prime \prime}$-; assim como se vê o descolamento do hospedeiro nesse jogo escritural - "Senti que teria agora de escolher entre elas. Minhas duas naturezas tinham uma memória em comum, mas todas as outras faculdades eram compartilhadas entre elas de forma desigual" - , presenciando a consequência das ações de seus outros - "Jekyll era agora minha cidadela de refúgio, porque se Hyde entremostrasse seu rosto por um só instante as mãos de todos os homens estavam prontas para agarrá-lo e fazer-lhe justiça".

Esse terceiro ser indicia o caráter múltiplo não só do corpo do alquimista, mas da própria narrativa. Como uma contaminação, dissemina os diversos índices da fragmentação não só no tema, mas também no nível estrutural do texto. Atendo-se ao campo da letra, o " $y$ " invade os nomes das duas personagens, duplamente nos nome e sobrenome do cientista (Henry Jekyll) e uma única vez no ente alienígena (Edward Hyde), evidenciando a união de três seres. Ao se visualizar a letra " $y$ ", pode-se depreender o encontro de três retas para um mesmo ponto: a tríade num mesmo corpo.

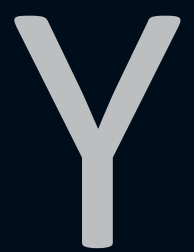




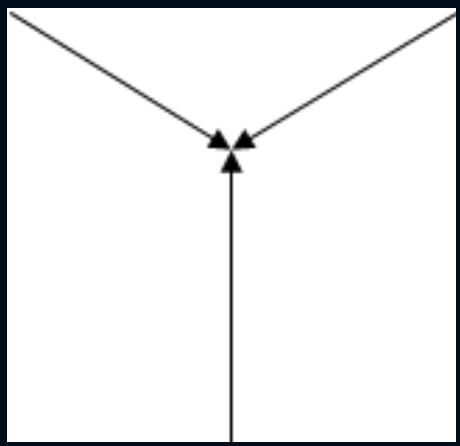

Figura 1. A letra triádica.

A casa de Henry Jekyll, prévia propriedade de um cirurgião, denota um esquema múltiplo: duas são suas entradas, cada uma usada por uma entidade. O respeitável Jekyll toma o portal da frente como seu acesso a casa, enquanto Hyde, às sombras, utiliza a porta dos fundos, onde a moralidade não governa. Além disso, o interior espacializa essa multiplicidade que permeia a narrativa ao denotar possibilidades diversas para o acesso ao escritório do cientista: o pátio interno, o anfiteatro cirúrgico e a escadaria; ou a porta dos fundos, o anfiteatro e as ditas escadas. Esse roteiro espacial, como se nota, fora infectado pelo potencial da droga. A fragmentação incrusta-se na própria casa. O percurso feito por Utterson, por exemplo, revela uma dessas estradas possíveis:

Foi apenas no final da tarde que Mr. Utterson conseguiu finalmente bater à porta da casa do Dr. Jekyll, onde foi imediatamente recebido por Poole e conduzido, através da cozinha, até um pátio interno que em outra época havia sido um jardim, e depois à construção que ficava nos fundos, e que tanto era denominada de "laboratório" quanto de "quarto de dissecação". [...] Tomado por uma sensação sinistra, ele entrou em um pequeno anfiteatro 
interno, onde tempos atrás estudantes ansiosos por conhecimento tinham se sentado, e que agora estava vazio e silencioso. As mesas estavam cheias de aparelhos químicos, o chão coberto por caixotes e pela palha usada para proteger as encomendas, enquanto a luz se escoava fracamente por uma claraboia embaçada. Na extremidade oposta, um lance de escadas subia até uma porta coberta de tecido vermelho, através da qual Mr. Utterson teve acesso ao escritório particular do doutor. (STEVENSON, 2011, p.45)

Outro aspecto, evidência do fragmento, é o jogo de documentos. Tomando o cofre de John Utterson como o tabernáculo máximo dos papéis em questão, o advogado tem-no como o guardião de três posses: o testamento de Henry Jekyll, no qual o médico oficializa Edward Hyde como seu herdeiro; a suposta carta de Hyde, em que sua assinatura afirma sua fuga eminente e o envelope lacrado de Hastie Lanyon, contendo outro envelope, o qual comporta a narrativa do nono capítulo, em cujo conteúdo insere-se a carta de Jekyll, informando o lugar da gaveta e a ordem de mistura dos sais e substâncias. Com esse jogo de guardião e guardado, hospedeiro e hóspede, encaixe e desencaixe, mise-en-abîme, a fragmentação não mais é um indício, mas se realiza na superfície ou estrutura do texto. 0 duplo não mais impera como possibilidade, ele é transformado, uma vez que o jogo "cofre-documentos", a partir de um processo metanarrativo, abre um leque de caminhos múltiplos. Sendo o cofre o arquivador do testamento de Jekyll - prova oficial da relação entre o cientista e o assassino - , da carta de Hyde - a afirmação de sua existência material, por meio da assinatura - 
e do duplo envelope de Lanyon - indiciando a inserção de um envelope dentro de outro, contendo o último a narrativa do olhar do outro sobre o segredo central, no seio da qual consta um outro texto -, esse item plasma o mesmo princípio que se alastrou pelo corpo que um dia dignara-se da ilusão da unidade.

O guardião desses três documentos, mais tarde, é confrontado por um outro conjunto de textos, novamente uma tripla combinação. Em "A última noite", o oitavo episódio do fio narrativo, Utterson encontra, no escritório de Jekyll, três documentos: um novo testamento, passando as fortunas do cientista ao advogado; um bilhete, no qual Jekyll instrui Utterson a ler, primeiramente, a narrativa de Lanyon e, secundariamente, de acordo com a vontade do detetive, sua confissão, e um envelope lacrado em vários lugares contendo o relato final. Assim, com esses diversos textos, materializa-se, nos vários níveis da narrativa, uma convergência do metatexto (um texto no interior do outro) com o fragmentário: um manto que inscreve em si a metatextualidade e a fragmentação; múltiplas centelhas que se lançam num labirinto abismal.

O assassinato de Sir Danvers Carew é duplamente triplo: Hyde, em seu acesso de fúria, dizima o parlamentar, fragmentando sua bengala. A presença de Hyde como personalidade consciente no corpo hospedeiro não excluía a presença de Jekyll nesse mesmo corpo, ainda que de forma inconsciente. Hyde, Jekyll e o corpo hospedeiro formam uma entidade trina. Há, então, a vítima - que se constitui como o quarto olhar da cena - e uma testemunha, uma criada de uma das casas próximas à cena do crime. Todas essas entidades sob os olhos de um narrador onisciente, outro às demais subnarrativas que compõem a macronarrativa intitulada $O$ médico 
e o monstro. Seis olhares - o do(s) assassino(s), uma entidade tripla, o da vítima, o da testemunha e o do narrador - constroem essa cena de horror, que se mostra, portanto, múltipla ao seu leitor:

[...] e ela ficou surpresa ao reconhecer nele um certo Mr. Hyde que certa vez visitara seu patrão e pelo qual ela passara a nutrir aversão [...]. No momento seguinte, com a fúria de um gorila, estava pisoteando o homem caído e cobrindo-o com uma saraivada de golpes tão fortes que se podia ouvir o ruído dos ossos partidos, enquanto o corpo do homem se estorcia em convulsões sobre o pavimento. Diante de uma visão e de sons tão horríveis, a criada desmaiou.

[...] O bastão com que o crime havia sido cometido, mesmo sendo de uma madeira rara e muito resistente, havia se partido ao meio devido à fúria daquele ataque cruel e insensato; uma das metades tinha rolado pelo chão até cair na sarjeta, e a outra, sem dúvida, havia sido levada pelo criminoso. (STEVENSON, 2011, p.40)

Nos desenvolvimentos interpretativos desse fluxo fractário, a chave utilizada pelo assassino durante seu perambular pela casa do médico tem um fim peculiar, como notado por Poole, o mordomo de Jekyll, e por Utterson:

- Usada! - ecoou Poole. - Não vê que está quebrada, senhor? Como se um homem tivesse pisado nela com força.

- Sim - disse Utterson -, e as fraturas, também, estão enferrujadas. - Os dois homens se entreolharam, com uma expressão de medo. (STEVENSON, 2011, p.70) 
O instrumento usado por Hyde não escapa da disseminação fragmentária e o próprio cientista a estilhaça, como o fizera a seu antigo corpo: "Com que renúncia sincera tranquei a porta por onde tantas vezes tinha entrado e saído, e parti aquela chave sob o salto da minha bota" (STEVENSON, 2011, p.98).

Em dado momento, relatando a Utterson, ao avistar Hyde, Poole confunde-o com Jekyll:

Ergueu os olhos quando me viu entrar, deu uma espécie de grito, e subiu as escadas correndo, trancando-se no escritório. Vi-o apenas durante um minuto, mas meu cabelo arrepiou-se todo. Senhor, se aquele era o meu patrão, por que motivo tinha uma máscara cobrindo o rosto? Se era meu patrão, por que guinchou como um rato, e fugiu de mim? Fui seu criado durante muito tempo. E agora... (STEVENSON, 2011, p.64 - grifo nosso)

Na visão do mordomo, enquanto manifestada a personalidade Hyde, uma máscara, assim percebida pelo olhar alheio, está pregada no rosto do famigerado. Uma máscara é a representação de um rosto, mas não necessariamente encobre um rosto "real", sendo esse objeto um símbolo de simulacro e simulação que não tem nenhum compromisso com a "realidade". Logo, um fragmento a mais impregna-se no corpo do trio que, desse modo, passa a ser quádruplo: manifestado Hyde, seu rosto assume a forma de uma máscara, um artefato que oculta e substitui uma face talvez inexistente, e adiciona mais um nível de proteção ao escudo de paralaxe do necromante, mais uma habilidade que se soma aos poderes que o permitem transformá-lo, levando em conta todo esse arsenal arcano e o elixir da vida, segundo o bestiário da ficção gótica, num lich: 
[...] uma criatura maligna, tipo específico de morto-vivo [...]. Trata-se, na verdade, de um ser humano que, em vida, buscou incessante e incansavelmente conhecimentos ocultos e proibidos, tendo se tornado, por meio dessa busca, um feiticeiro muito poderoso, um rei ambicioso ou ambas as coisas. Não contente com sua condição humana, em tudo limitada e limitadora dos seus ideais de poder incondicional e infindo, esse humano utilizou os conhecimentos herméticos que adquiriu para se tornar imortal e eterno por meio de um ritual de necromancia que, se efetuado com sucesso, resulta na transformação do que era mortal e perecível em imortal e imperecível. (ROSSI, 2015, p.134)

A fragmentação começa, desse modo, a contaminar o entendimento que se tem das personagens e personalidades de Jekyll e de Hyde.

A própria droga, em seu estágio de preparação, também indicia essa disseminação da fragmentação, pois três mudanças tonais, e, por extensão, a existência de quatro cores perfazem o processo necessário para a (im)perfeição, como notado por Lanyon:

Ele me agradeceu com um aceno e um sorriso, derramou no tubo uma pequena quantidade do líquido vermelho, e despejou ali um dos preparados em pó. À medida que os cristais se dissolviam, o líquido foi tomando uma cor mais clara, enquanto se elevava dele uma audível efervescência e um pouco de vapor. De repente essa ebulição cessou por completo, enquanto assumia uma tonalidade de púrpura escuro, que foi aos poucos mudando para um verde aquoso. (STEVENSON, 2011, p.82 grifo nosso) 
Ainda no que concerne a esse fármaco, na confissão, o(s) seu(s) autor(es) inicia(m) uma linha de pensamento que incita o fragmentar:

Naquela noite cheguei à encruzilhada fatal. Se tivesse empreendido a minha descoberta com espírito mais nobre, se tivesse me arriscado naquela experiência quando sob a influência de aspirações generosas ou piedosas, tudo poderia ter sido diferente, e, daquelas agonias tão intensas quanto as da morte e do nascimento, eu poderia ter emergido como um anjo, ao invés de um demônio. A ação da droga não discriminava; não era em si diabólica nem divina; ela apenas arrombava as portas da prisão da minha vontade; $e$ como os cativos de Filipos, aquele que estava mais pronto foi o primeiro a fugir. Naquele momento minha virtude cochilava; minha maldade, mantida desperta pela minha ambição, estava alerta e pronta para aproveitar a ocasião; e a criatura que foi projetada foi Edward Hyde. Daí que, embora eu tivesse duas personalidades, bem como duas aparências, uma delas era totalmente maligna, e a outra era ainda o velho Henry Jekyll, aquele misto incongruente que eu já perdera as esperanças de mudar e aperfeiçoar. O movimento ocorrido, portanto, foi totalmente para o pior. (STEVENSON, 2011, p.90 - grifo nosso)

Mais do que se decidir entre o bem e o mal, a tintura de Jekyll - "Eu já havia há muito tempo preparado a minha tintura" (STEVENSON, 2011, p.88 - grifo nosso), diz uma citação já feita outrora - manifesta-se da mesma forma que Jacques Derrida lê o phármakon no diálogo Fedro, de Platão, em seu livro A farmácia de Platão (“La pharmacie de Platon”, 1968): “O phármakon e a escritura são, pois, sempre uma questão de vida [e] de morte" (2005, p.52). Mantendo-se na indecisão entre esses 
dois pólos, a substância de Jekyll não entra, nas suas palavras, numa valoração opositiva, já que ao invés do monstro luciferino, um ente celestial poderia emergir desse experimento. Assim, a droga, seja ela veneno ou remédio ou ambos, é indecidível: não há uma vereda escolhida, como no poema "O caminho recusado" ("The Road Not Taken", 1916), de Robert Frost, mas somente a abertura das portas e então a eterna permanência na encruzilhada da existência, muito mais próxima ao que faz Emily Dickinson em "Nossa jornada avançara-" ("Our Journey Had Advanced-", 1891). Os antípodas não se neutralizam e passam a assomar um ciclo interminável de hesitação, no qual extremos ou sínteses ausentam-se e somente há o(s) entre(s): "Bem antes de ser dividido em violência oculta e saber justo, o elemento do phármakon é o lugar do combate entre a filosofia e seu outro. Elemento nele mesmo, se podemos ainda dizer, indecidível" (DERRIDA, 2005, p.88 - grifo do autor).

É esse elixir que possibilita a abertura do portal do cárcere volitivo e de lá a vinda de Edward Hyde. Note-se, no trecho do romance mencionado anteriormente, que ele seria o primeiro a sair - "[...] e como os cativos de Filipos, aquele que estava mais pronto foi o primeiro a fugir". O que leva à(s) pergunta(s): se Hyde fora o primeiro a fugir e, por consequência, a ser materializado, o que mais existiria nesse repositório do phármakon? Quem são os espectros imaterializados ainda aprisionados? Estariam tais seres ainda presos? A poção somente arrombara tais portas, não pressupondo, pelo menos nas palavras confessionais desse relato, um lacre depois da saída de Hyde, pois o movimento que o liberou fora de ordem explosiva. Dessa forma, o phármakon 
jekylliano, arrombando o portão infernal das vontades, permitira que o teratológico se manifestasse na corporeidade de Jekyll, porém, sem encerrar essas portas, possibilitando, como se reitera em vários elementos que se veio discutindo (o múltiplo e o fragmentário nos documentos, no corpo da tríade, na linguagem escrita no relato confessional), um alastramento brutal dessa multidão encarcerada que foge pelas frestas do texto-portal, fantasmas que viralizam e contaminam as várias instâncias dessa narrativa, estigmatizando suas vítimas com um rastro fragmentário multíplice, inclusive o próprio corpo do qual se abjugou. Em termos mais (meta)físicos:

A magia da escritura [...] é, pois, aquela de um disfarce que dissimula a morte sob a aparência do vivo. O phármakon apresenta e abriga a morte. Ele dá boa figura ao cadáver, o mascara e disfarça. Perfuma-o com sua essência [...]. O phármakon designa também o perfume. Perfume sem essência, [...] droga sem substância. Ele transforma a ordem em enfeite, o cosmos em cosmético. A morte, a máscara, o disfarce, é a festa que subverte a ordem da cidade, tal como ela deveria ser regulada pelo dialético e pela ciência do ser.

[...] O esperma, a água, a tinta, a pintura, o tingimento perfumado: o phármakon penetra sempre como o líquido, ele se bebe, se absorve, se introduz no interior que ele marca, primeiramente, com a dureza do tipo, invadindo-o em seguida e inundando-o com seu remédio, sua beberagem, sua bebida, sua poção, seu veneno.

No líquido, os opostos passam mais facilmente um no outro. O líquido é o elemento do phármakon. $\mathrm{E}$ a água, pureza do líquido, se deixa o mais facilmente, o 
mais perigosamente, penetrar e depois se corromper pelo phármakon, com o qual se mistura e se compõe tão rapidamente. (DERRIDA, 2005, p.92-102)

Nas cenas finais do referido capítulo oito, Poole e Utterson, ao arrombarem o escritório de Jekyll, encontram um ambiente em caos e um cadáver. Neste momento, o corpo trino estava configurado como Edward Hyde, e um objeto intrigante completa a ambientação:

Em seguida, no curso do seu exame, os dois se aproximaram do grande espelho, que contemplaram com involuntário horror. Mas o espelho, que era montado sobre gonzos de modo a girar verticalmente sobre si próprio, estava apontando para o teto, mostrando nada mais do que o brilho rosado das chamas bruxuleando no teto, as mil cintilações criadas pelo fogo ao longo dos armários envidraçados, e os seus próprios rostos, pálidos e temerosos, debruçando-se para olhar.

- Este espelho deve ter visto algumas coisas estranhas, senhor - sussurrou Poole.

- E com certeza nenhuma mais estranha do que ele próprio - respondeu o advogado no mesmo tom. - Senão vejamos, por que motivo Jekyll... ele se interrompeu com um sobressalto ao dizer esta palavra, mas logo se recompôs desta fraqueza - ... para que Jekyll precisaria dele aqui?

- Bem observado - disse Poole. (STEVENSON, 2011, p.71)

O que se vê aqui é a máxima potência, o próprio conjuro do necromante em ato, da fragmentação. O espelho em questão, materializando em sua grande corporeidade as imagens de 
Utterson, Poole, das chamas e do cadáver, devido a uma inclinação, reflete esse imaginário nos vidros dos armários presentes no local, criando infinitas reflexões de reflexões. A luz, provinda das chamas e múltipla em si, já que espectro luminar que agrupa o continuum das cores do arco-íris lança-se ao objeto catóptrico, contribuindo na disseminação da multiplicidade ao longo do gabinete, a qual é exacerbada pelos vidros dos armários e pela quadratura representacional (Jekyll, Hyde, hospedeiro, máscara) sucumbida. A pura fragmentação, o só-refletir, rompe as barreiras da realidade factual e abre suas asas para sua performance suprema. A fragmentação do múltiplo pelo espelho, contaminado pelo fragmentário e transmissor dele, transcende o terceiro elemento do Complexo de William Wilson: o espelho não mais é responsável pela reflexão de um par, mas por pares de pares ad infinitum, ad absurdum, subvertendo e corrompendo o império da duplicidade.

Ademais, no momento da escrita de sua confissão, é mencionado que a já quadratura representacional está diante do espelho referido previamente: "Não havia espelho no aposento, naquela época; este que agora está diante de mim enquanto escrevo foi trazido para cá bem depois, com o propósito de acompanhar estas transformações" (STEVENSON, 2011, p.88). Do autor à página, da página ao espelho - novamente se dá a reduplicação de uma relação quádrupla, agora por meio da reflexão da escritura confessional. Nesse caso, uma autoficcionalização, a ficcionalização da quadratura por ela mesma, é virtualizada, um ficcionalizar de si no interior de um universo especular, a dimensão da catoptricidade.

Com essas cenas e com o que se apresentou até aqui, a insurgência de um só-paradoxo, ou um paradoxo de paradoxos, é 
iminente: o que ora denominamos "Paradoxo Jekyll-Hyde" insurge e, dimanante disso, consome a dupla existência, o duplo caso, o trio e o quádruplo. O Complexo de William Wilson é revisado, inovado e ampliado exponencialmente, com uma carga significativa colossal. O Doppelgänger perde suas forças e dá lugar ao puro fluxo da fragmentação. Somente o refletir da reflexão manifesta-se, apontando que não há um primeiro eu e um segundo eu, mas uma proliferação incontrolável, uma disseminação contaminadora, de eus que, em seu conjunto, não compõem um nós ou um eles, não compõem conjuntos harmônicos de sujeitos ou objetos, de modo que o reflexo independe daquilo que é refletido, o reflexo ganha independência em relação ao refletido, apontando para um sófragmento que é também um só-fragmentar. Como a quadraturaautor relata, "Outros me seguirão, outros irão me ultrapassar nesse caminho; e eu arrisco a suposição de que o homem acabará sendo reconhecido como uma assembleia de inquilinos múltiplos, incongruentes e autônomos" (STEVENSON, 2011, p.86). Com tal afirmação presente na textualidade de 0 médico e o monstro, temos, além da morte do duplo ou sua transmutação em múltiplo, a ascensão da Era do Fragmento, a era do simulacro e da simulação, ou a própria contemporaneidade, adiantada em quase cem anos em relação aos pós-estruturalistas e às teorizações de Jean Baudrillard.

A obra máxima de Stevenson pode ser considerada, portanto, para além de uma manifestação tardia do Romantismo na literatura inglesa e de um marco na tradição da literatura gótica ocidental, um dos textos fundadores dos paradoxos da pós-modernidade, um dos textos fundadores da contemporaneidade. Talvez essa sua capacidade de disseminar alteridades aterrorizantes, teratologias 
incontroláveis, seja uma das razões pelas quais $O$ médico e o monstro continua se constituindo como o outro da ficção contemporânea, desdobrando-se atualmente em infinitas adaptações, referências, reinscrições, releituras, que abrangem suportes tão variados como o cinema, o teatro e as séries de televisão.

\section{REFERÊNCIAS}

BOTTING, Fred (1996). "Introduction: Gothic Excess and Transgression". In: . Gothic. New York; London: Routledge. (The New Critical Idiom). p.1-20.

BORBA, Francisco da Silva (Org.). (2004). "Paralaxe". In: . Dicionário UNESP do português contemporâneo. São Paulo: Editora UNESP. p.1025.

ECO, Umberto (1989). "Sobre os espelhos". In: Sobre os espelhos e outros ensaios. Rio de Janeiro: Nova Fronteira. p.11-37.

FREUD, Sigmund (1996). "O "estranho"”. In: . Edição standard brasileira das obras psicológicas completas de Sigmund Freud. Rio de Janeiro: Imago, v. XVII. p.233-273.

JUNQUEIRA, Renata Soares (2004). O complexo de "William Wilson": crise de consciência e perquirição de identidade no moderno teatro português (resumo de projeto de pesquisa). [S.I]: [s.n.]. In http://www2.fclar.unesp.br/ centrosdeestudos/gpd/. Acesso em 15.Mar.2013.

LACAN, Jacques (1998). "O estádio do espelho como formador da função do eu". In: Escritos. Rio de Janeiro: Jorge Zahar. p.96-103.

RANK, Otto (2013). O duplo: um estudo psicanalítico. Porto Alegre: Dublinense. ROSSI, Aparecido Donizete. Ressurectum de Tenebris: o Lich na Ficção. Abusões, Rio de Janeiro, v.1, n.1, p.122-154, 2015. Inhttp://www.e-publicacoes.uerj.br/ index.php/abusoes/article/view/20429/15241. Acesso em 10.Jul.2016.

SOUZA, Vinicius Lucas de. (2016). "Jekyll e Hyde: Alquimia e Feitiçaria". In: Colóquios de Estudos em Narrativa: A ficcionalização do medo na narrativa. 4. ed.Anais do CENA. Uberlândia: EDUFU, v.2. p.1-10. In http://www.ileel.ufu. br/anaisdocena/wp-content/uploads/2016/01/Vinicius-Lucas-de-Souza.pdf. Acesso em 10.Set.2016. 
SOUZA, Vinicius Lucas de; ROSSI, Aparecido Donizete (2015). A emergência do Complexo de William Wilson. Revista Vocábulo, Ribeirão Preto, n. IX, p.1-19. In http://www.baraodemaua.br/comunicacao/publicacoes/vocabulo/pdf/nono/7_ vinicius_volume_IX.pdf. Acesso em 10.Set.2016.

STEVENSON, Robert Louis (2011). O estranho caso do Dr. Jekyll e Mr. Hyde. Trad. Braulio Tavares. São Paulo: Hedra. 